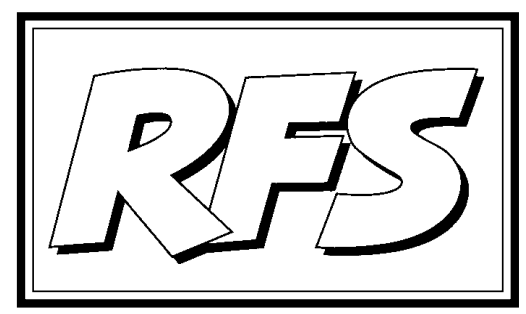

Revista de Fomento Social, 55 (2000), 569-586

\title{
Diez años de reflexión y acción social de la Compañía de J esús en el cambio de siglo (1989-2000)
}

J osé Ma MARGENAT PERALTA SJ

Las recientes jornadas de Alcalá de Henares cerraban un proceso de relectura de la misión de la Compañía de Jesús y abrían una nueva etapa: vivimos en un tiempo de recuperación de identidad para la misión de la justicia-un sector social visible e institucionalmente significativo-, en que se nos invita a acoger con imaginación profética, nuevos modos de presencia de la misión de la Compañía de J esús, seglares y jesuitas juntos.

El conocimiento y reflexión sobre lo que ha vivido la Compañía en España y Portugal ${ }^{1}$, en estos últimos diez años, situado en su contexto mundial,

* Profesor de Pensamiento Social Cristiano en la Facultad de Ciencias Económicas y Empresariales - ETEA, Córdoba.

1 Este proceso ha sido participado por las seis provincias hispánicas y por la provincia portuguesa desde el principio, por lo que nos referiremos a su conjunto, aunque no puedan olvidarse las diferenciaciones propias de cada nación y de cada provincia como instancia apostólica. 
puede servir para interpretar la actualidad de nuestros retos y para pensar adecuadamente las dimensiones de nuestra respuesta.

La Compañía de Jesús inició a finales de los 80 una reflexión profunda sobre cuál fuese la mejor formulación y realización de su misión. No fueron circunstancias fáciles, aunque el ambiente interno de la Orden se había sosegado tras la crisis de los primeros años 80. La situación de excepción padecida por la Orden, tras la enfermedad del padre Arrupe y el nombramiento de un delegado papal y un coadjutor para gobernar excepcionalmente la Compañía, se habían cerrado en 1983 con la elección de un nuevo general, el neerlandés-libanés Peter-Hans Kolvenbach. La respuesta obediente y libre, de acuerdo al modo de proceder ignaciano de fidelidad crítica, y después, la vuelta a la normalidad institucional de gobierno, habían logrado recuperar la confianza y la capacidad de poner en marcha proyectos de alcance. En septiembre de 1990 se tuvo en Loyola una asamblea de todos los responsables territoriales de la Compañía, junto con el equipo dirigente central (Congregación de provinciales, primera y única en la historia). Comenzaban también aquel año los aniversarios ignacianos: quinientos años del nacimiento de san Ignacio en Loyola (1491) y cuatrocientos cincuenta años del documento pontificio de aprobación de la Compañía (Regimine militantis Ecclesiae de Paulo III, 1540). La Compañía era invitada a leer los signos de los tiempos y a reaccionar a las nuevas demandas sociales, culturales y espirituales del giro de siglo, retornando a la misión fundamental, definida por el Papa Paulo III y confirmada posteriormente. Así la fórmula de la misión que la Compañía había afirmado durante el tiempo del padre Arrupe, cumpliendo con el mandato del Concilio Vaticano II de retornar a la identidad fundacional y con el encargo papal de Pablo VI de comprometerse en la lucha contra el ateísmo, era convocada a una nueva relectura. Esta actitud de examen estaba muy presente a principios de los años 90, cuando empezaba el giro de siglo, y lo estuvo también en la Compañía.

El clima cultural imperante invitaba a un examen del camino recorrido - lo que, por otra parte, entroncaba con elementos muy nucleares de la espiritualidad ignaciana- y a reorientar las opciones en orden a una mayor fidelidad y a la renovación en la misión. En las páginas que siguen presentamos los diferentes momentos de esta evolución, siendo conscientes de que se trata de un camino abierto en el que la Compañía de J esús, en el ámbito mundial y en el hispánico, sigue comprometida en una búsqueda. En las páginas que siguen nos encontraremos primero con una breve visión de la evolución de la Compañía en los quince años que

\section{RFS}


preceden al período estudiado, para entrar después en un análisis más pormenorizado del último decenio.

\section{La evolución de la cuestión social en la Compañía de J esús de 1975 a 1990}

Después del Concilio Vaticano II la Iglesia toma conciencia de que no se puede hablar seria y cristianamente de Dios si al mismo tiempo no se habla de la lamentable situación de un número impresionante y creciente de hombres y mujeres. La palabra del evangelio se torna increíblesi los ho mbres de nuestro tiempo no se encuentran a los cristianos jugándose su vida en los mismos sitios donde se juega también la existencia y el futuro de sus hermanos ${ }^{2}$. Difícilmente pueden creer que lo que anunciamos sea una buena noticia -en palabras de Pablo VI- si no tiene que ver nada con la experiencia lamentable del hambre endémica que mancha la humanidad, con las guerras que deshacen un mundo creado para la comunión, con el destrozo del hábitat, convertido en un sitio desastroso para la convivencia. No se puede nombrar a Dios honestamente, si al mismo tiempo quienes dicen creer en él no se disponen a servir a la justicia, la solidaridad, la misericordia y el amor, en los lugares de peligro de la humanidad.

La Iglesia toda reflexionó y puso delante de Dios su conciencia de la misión en la Asamblea del Episcopado latinoamericano de Medellín (1968) y en el Sínodo de los obispos de 1971. Ambos acontecimientos influyeron fuertemente en los jesuitas. La 32a Congregación general de la Compañía -la asamblea legislativa suprema- recibió esta convicción conciliar, reafirmada por el Síno do de la justicia de 1971, como al go dirigido a su propia renovación, y la plasmó en el famoso decreto 4ํㅜ que no era una arbitraria decisión de los 230 jesuitas reunidos en Roma en 1974 y 1975, sino respuesta a las peticiones llegadas de lugares tan diferentes como África, India o Norteamérica. Todas las relaciones enviadas a esta Congregación expresaban una nueva conciencia apostólica de la Compañía (Kolvenbach): la preocupación por el olvido de Dios y por la injusticia social.

En 1975 no se habían producido aún ciertos cambios mayores que en los años inmediatamente posteriores iban a configurar otro mundo. Esto explica que relativamente pronto vaya a superase el marco desde el que reflexionó la asamblea de los jesuitas. Aquellos cambios fueron de orden político,

2 Octogesima adveniens no 51, 14 de mayo de 1971. 
cultural y religioso: la reapertura del espacio de diálogo en Europa, con todo lo que significó y generó el movimiento del Acta Final de Helsinki, como encuentro de los países democráticos y capitalistas y los colectivistas y totalitarios; la configuración de los derechos como horizonte de universalización de la justicia, lo que significa que no se puede hablar de justicia social si se violan los derechos humanos, y que estos, para no ser meramente declamados, han de realizarse históricamente en la justicia; la revalidación de la enseñanza social cristiana como instrumento de análisis de la realidad y como propuesta para construcción de la realidad social, que no se pretende alternativa a los sistemas existentes, sino propuesta crítica para el debate; la nueva conciencia de interdependencia y de solidaridad internacional necesaria para un afrontamiento lúcido y cristiano de la situación mundial; la creciente desigualdad del Sur, que año tras año, desde 1991, es analizado por el PNUD [Programa de las Naciones Unidas para el Desarrollo] añadiendo un refuerzo de realismo a la antes citada conciencia de interdependencia estructural de los sistemas económicos y de la necesaria solidaridad para cualquier intento serio de respuesta; la transformación de los movimientos históricos de lucha por la justicia, sea en el mayor protagonismo que en el Este marxista toman los movimientos civiles de defensa de los derechos humanos, sea con la conciencia más profunda del cambio histórico a realizar, con sus exigencias de una espiritualidad del tiempo largo y una capacidad de disciplina histórica para acometer transformaciones de hondo calado; la feminización dela pobreza, los derechos de los pueblos indígenas, el derecho al desarrollo, los problemas del cuidado ambiental y el desarrollo sostenible, la paz.

Para cualquier lector estas referencias le habrán evocado los llamados derechos humanos de tercera generación o derechos de la diferencia: los relacionados con el ambiente, el género, la ecología, la paz, etc., así como los llamados nuevos movimientos sociales, oleada en que, posteriormente, habría que incluir el movimiento de las ONGD y el del voluntariado, que han sido la respuesta más característica a esta nueva e inmensa problemática.

En estos quince años la Compañía vivió una intensa polarización en torno al binomio fe-justicia y adquirió una conciencia nueva de la diversificación de la lucha por la justicia. Hoy tenemos una conciencia integral de la misma, que nunca se opone a la libertad. Libertad e igualdad, justicia y dignidad de la persona humana, no pueden separarse. Los derechos humanos son inseparables y no son negociables. La cultura de la solidaridad, la carta de ciudadanía que adquiere la conciencia ecológica, la

\section{RFS}


integración del cambio cultural entre las dimensiones de la justicia, la vinculación entre la justicia y la vivencia teologal de la misma como una dimensión necesaria para no defraudar la dinámica histórica creada por la llamada del Evangelio son elementos de esta conciencia. Tras esta evolución, evocada sumariamente, y en este contexto, se desarrolla el proceso de los últimos diez años en España, del que vamos a dar cuenta más detenidamente. Al referirnos a los distintos momentos colectivos en que la Compañía española y portuguesa han ido dando pasos, iremos intercalando los hechos centrales de toda la Orden en el ámbito mundial, que condicionan y van dando la pauta y el ritmo, ante los que los jesuitas de la península ibérica van ensayando sus respuestas.

\section{Cultura de la solidaridad y misión de la Compañía (Gijón, 1990)}

En esos últimos diez años ha habido una evolución en la reflexión y en la acción social de la Compañía de J esús. Los propios procesos internos vividos desde la misión de la Compañía, así como el contexto histórico en que estos se sitúan, permiten explicar el cambio acaecido en el giro de siglo. En noviembre de 1989 cayó el muro de Berlín -fecha y símbolo, al mismo tiempoy se iniciaron una serie de transformaciones en la cultura, la percepción social de lo real y la dinámica histórica, que son objeto de análisis continuado desde entonces. Términos, muchos de ellos efímeros, como fin de las alternativas, Estado débil, pragmatismo, pensamiento único, tercera vía, crisis del Estado de bienestar, neoliberalismo, fin de la historia, revolución tecnológica, Estado ligero, fragmentación social, exclusión, sociedad de los dos tercios, globalización, nuevo orden informativo, mundialización, homogeneización cultural, interculturalidad, conservadurismo compasivo, multiculturalidad, etc., han estado presentes en el debate, en las propuestas y en la acción política de estos diez últimos diez años. La propia Compañía de J esús no podía sustraerse a esta evolución.

En 1990 comenzaron los aniversarios ignacianos a que antes nos hemos referido. El padre general quiso que, con esta ocasión, la Compañía, lejos de cualquier retórica y exterior triunfalismo, se movilizase en un intenso esfuerzo sobre dos cuestiones esenciales: la espiritualidad ignaciana como fuente de vivificación de la vida y del compromiso apostólico de los jesuitas y, en segundo término, el retorno al carisma fundador de la misma en un movimiento que, en el año 2000, ha venido a denominarse refundación de la Compañía o afirmación de la fidelidad creadora en la conciencia apostólica 
de la Orden. Era éste un movimiento iniciado a partir del Concilio, que en otros ámbitos religiosos se formuló en estos o similares términos, de parecida forma a otros procesos de refundación de la democracia o de la axiología educativa en ámbitos seculares.

Del 28 al 30 de diciembre de 1990 se tuvieron en Gijón las TercerasJ ornadas Fe-J usticia, organizadas por la Comisión social de los mencionados aniversarios, y en continuidad con otras dedicadas al tema Fe-Increencia (febrero de 1986) y sobre Increencia y medios de comunicación social (enero de 1989). A estas seguirían, cuatro años más tarde, unas III J ornadas Fe-Increencia, en Majadahonda (septiembre de 1994), estas ya en el mismo clima que el Foro de Alcalá '94, al que aludiremos después. En las Jornadas de Gijón de 1990 tomaron parte 130 jesuitas españoles. El año anterior se había realizado una Encuesta sobre el tema Fe-J usticia, cuyos resultados fueron presentados en las J ornadas. Todavía en estas J ornadas se insistía en que el servicio de la Fe y la promoción de la Justicia debían integrarse en todos los apostolados de la Compañía, constituyendo la forma omnium (el principio común integrador) de la Compañía. La primera ponencia Fe-J usticia: Quince años después, presentada por J.I. González-Faus en nombre de Cristianisme i Justícia de Barcelona, constataba los siguientes hechos y situaciones:

1ㅇ. En el campo de la reflexión como de la acción, no se acaba de atacar el problema en sus causas más de fondo, y "parecemos condenados a quedarnos en acciones puntuales, fragmentarias, periféricas, que dejan casi intocado el gran problema de la injusticia estructural".

2ํ. La proclamación profética del pecado estructural y la orientación de nuestras vidas deben mantenerse en las mismas grandes opciones de 1975, aún contando con los cambios producidos en el mundo.

30. En los últimos quince años se han producido una serie de cambios importantes tanto en lo cultural como en las ciencias sociales: cultura de la postmodernidad, paso de lo profético a lo sapiencial, necesidad y esfuerzo de discernimiento en la utilización de las ciencias sociales.

4․ La experiencia y la conciencia de injusticia que tienen los que padecen a nuestro lado, con quienes nos compadecemos, nos llevan a comprometernos en la lucha contra el mal del hermano "como si fuera mi propio mal", como exigencia absoluta de la paternidad de Dios, generadora de fraternidad y de experiencia espiritual.

En estas Jornadas se subrayaron algunos elementos que sintetizamos a 
continuación y que a los jesuitas participantes pareció que podían orientar la acción y la reflexión de los años venideros: ensanchamiento en los horizontes de la justicia y universalización histórica por el camino de la solidaridad; recuperación de la dimensión privada en la profundidad de las dimensiones de la persona; límites y posibilidades del contexto eclesial en que se realiza nuestra opción por la justicia; necesidad de construir una voluntad colectiva para desarrollar este compromiso; necesidad de la lucha cultural contra la lógica prevalente de la insolidaridad; necesidad de romper contra el blindaje de la injusticia occidental; reafirmación de la opción fejusticia de la 32a Congregación General; necesidad de encontrar cierta claridad para situarnos, de verdad, del lado de la defensa de los derechos de los pequeños, que es donde se da el crecimiento del Reino de Dios, ya que todo lo que hagamos y planifiquemos debe tener presente el efecto que va a provocar en los más pequeños y más pobres.

En sus palabras de clausura, el asistente de España, Urbano Valero, destacó que se había visibilizado que la misión Fe-J usticia es misión y opción de todos, no una misión sectorial o de unos pocos, sino misión de todo jesuita. Aunque algunos sienten una especial Ilamada para trabajar en sectores que han servido para movilizar, para dinamizar a toda la Compañía, se subraya con fuerza que ésta es una misión común de todos - lo que en la terminología posterior se denominó dimensión-, y que para contribuir a una cultura de la solidaridad debe construirse primero una solidaridad corporativa como Compañía embarcada en una misión común.

\section{Hombres y mujeres competentes, conscientes, compasivos y comprome-} tidos (Documento Pedagogía Ignaciana 1993)

En 1986 el Consejo Internacional de la Educación S.I. (ICAJE) publicó las Características de la Educación de la Compañía de J esús. Siete años más tarde apareció otro documento educativo que respondía a la cuestión ¿cómo se pueden incorporar los ideales ignacianos a una pedagogía práctica? El documento Pedagogía ignaciana. Un planteamiento práctico forma con el anterior un equivalente para el tiempo actual, de la clásica Ratio studiorum institutionisque (la ordenación de los estudios y de la formación en los colegios de jesuitas) de la Compañía que vió la luz en 1586 y, ya en su versión definitiva, en 1599. Como lo fue durante más de tres siglos la Ratio studiorum, también ambos documentos actuales proponen un proyecto educativo para la educación en los centros de la Compañía de J esús. Por extensión podrían 
servir para cualquier proyecto educativo, incluso en la enseñanza no formal o en la universitaria, que quisiese inspirarse en la pedago gía y en la espiritualidad ignacianas.

El modelo educativo (paradigma pedagógico ignaciano) parte de esta pretensión: el objetivo último de la educación es un crecimiento global de la persona que lleva a la acción: la formación de hombres (y mujeres) para los demás según el padre Arrupe, líderes en el servicio y en la imitación de Cristo J esús, hombres y mujeres competentes, conscientes y comprometidos en la compasión, en palabras de Kolvenbach. El modelo ignaciano educativo es un 'modo de proceder' orientado a la reflexión y la acción de los alumnos, comprometidos en la transformación del mundo, que estructura un proceso continuo en cinco pasos: contexto del aprendizaje, experiencia de aprendizaje, reflexión sobre el proceso, paso a la acción y evaluación continua del proceso. Este modelo tiene su eje diferenciador y focalizador en el binomio reflexión-acción: la reflexión de la pedagogía ignaciana sería un proceso truncado si terminase en la mera comprensión conceptual y en las reacciones afectivas. La reflexión ignaciana parte precisamente de la realidad de la experiencia y termina necesariamente en esa misma realidad para actuar sobre ella; la educación que se pretende en los colegios de la Compañía está firmemente orientada a la acción y al compromiso social. Este documento ha supuesto un refuerzo y un impulso para muchos proyectos educativos de centros de la Compañía y para proyectos concretos de cooperación internacional, voluntariado social, servicio en tercer y cuarto mundos, educación social, etc. Pero este documento aún ha de influir muchísimo en la transformación y orientación sociales de los colegios y ha de contribuir a la presencia sólida de la dimensión social en todo el importante sector educativo de la Compañía de Jesús. Por otro lado, su orientación global y su puesta en práctica pueden resultar muy dinamizadores para el sector social, por lo que éste no debiera ignorar la existencia de este documento y de las realidades generadas a partir de él.

\section{Hacia la relectura de la opción fe-justicia (Foro Fe-justicia, Alcalá 1994)}

El clima en que celebraron estas J ornadas fue el de preparación de la 34a Congregación general. Como es sabido, en la misma, por la vía de cuatro decretos fundamentales se dio paso a un proceso doble: reafirmación de la definición de la misión de la Compañía que había hecho la 32a Congregación general (1974-1975) y que había sido confirmada por la Santa Sede, por la 33ạ

\section{RFS}


Congregación general (1983) y por la Congregación de Provinciales (1990) y, en segundo lugar, apertura a nuevas orientaciones en el compromiso por la justicia. En las Jornadas de Alcalá participaron unos 70 jesuitas, entre los cuales estaban los provinciales y los elegidos para la 34a Congregación General, de todas las provincias de España y de Portugal. Este foro había sido largamente preparado por la Comisión Nacional de Acción Social (CONAS) de la Compañía en España. De hecho esta Comisión de consulta del Provincial de España había nacido en enero de 1993 con el objetivo principal, entre otros, de preparar un foro sobre la misión de la Compañía y la justicia antes de la Congregación General. El Foro intercaló un tiempo de reflexión y diálogo, con amplio tiempo de oración personal y comunitaria. El Foro, en un anticipo de una orientación que iba a marcar a la propia Congregación general, se abrió con la intención y la perspectiva de examinar nuestra vida, para lo que hubo una ponencia de metodología ignaciana. Tres ejercicios de prelectura del material enviado por las provincias a la Congregación general (postulados) fueron seguidos de una ponencia sobre la realidad mundial y la solidaridad posibledesdela sociedad española y una invitación a contemplar este mundo desde la Encarnación de Dios. La experiencia de aunar diálogo y oración hizo posible una nueva mirada sobre la realidad de la misión de la Compañía.

La mirada a esta minima Societas ${ }^{3}$ hizo descubrir que las realizaciones, aunque pobres y fragmentarias, iban calando en la Compañía, al tiempo que la Compañía iba siendo cada día más consciente del precio que había de pagar por este compromiso: la conflictividad, cada día mayor, con ciertas instancias jerárquicas eclesiásticas, y la densidad de un camino difícil, intenso y abierto sólo a la confianza puesta en Dios, que la hacía salir de territorios de seguridad. La orientación impulsada por la 32a Congregación general era ya un proceso irreversible. Aún así, las resistencias observadas eran muchas: en el campo personal, en la vida comunitaria, en la incapacidad para una acción por la Fe y la Justicia que fuese a las raíces estructurales de los problemas, en la dificultad del lenguaje. Pero las posibilidades también eran enormes: seguir adelante con las experiencias radicales de comunidades de inserción, intercomunicar las propias realidades y experiencias

3 Minima societas, o mínima Compañía, es la expresión de cuño ignaciano que fue recuperada con intensidad por el padre Kolvenbach en la preparación de la Congregación general 34. La intención expresamente declarada por el padre general era, lejos de cualquier autocomplacencia narcisista o encubridora de soberbia, la búsqueda de una simplicidad evangélica en la Compañía y en la manera libre de relacionarse con los medios apostólicos. 
plurales - uno de los grandes capitales de la Compañía- superando la fragmentación y desarrollando una mayor acción 'sinérgica' (en los campos de la colaboración con los seglares, el voluntariado, etc.). Aún así los jesuitas eran conscientes de que nuestro mayor riesgo -y nuestro pecado colectivopodría estar en quedarnos en las palabras y no comprometernos con los hechos, algo ante lo que ya nos había avisado san Ignacio en el final de su libro de los Ejercicios 4.

Desde estas convicciones el Foro se decantaba por valorar y apoyar una praxis eficaz y modesta, realmente existente, y no dar pasos atrás, a pesar del clima social y eclesial existente, al tiempo que, desde la espiritualidad emergente, se iba acompañando este itinerario, de manera que la Compañía viviese el cambio provocado por el decreto 4 으o com don de Dios y como una tarea encomendada por el Señor que había de ofrecer a Dios. La reconciliación con la realidad, mirada con los ojos de Dios, y la libertad para seguir buscando la voluntad de Dios, sin ceder a las grandilocuencias, a la coartada de la complejidad, a la falta de concreción, sino buscando ampliar el consenso Fe-Justicia jesuita en cada provincia, abrirnos a todos los ámbitos populares, seculares, etc., y renovar la dimensión sociopolítica de nuestro compromiso por la Justicia, eran las dos claves apuntadas en el Foro Alcalá '94.

\section{Una única misión -servicio de la fe y promoción de la justicia- compar- tida y ensanchada (Congregación general 34ạ, Roma 1995)}

La asamblea suprema de representación de toda la Compañía -la 34a Congregación general, Roma, 5 de enero a 22 de abril 1995- tuvo muy en cuenta lo ocurrido en los veinte años que mediaban entre la 32a Congregación general (1974-1975, que aprobó el conocido Decreto 4ㅇsobre La misión de la Compañía, hoy) y aquel momento. A la luz de la múltiple y variada experiencia actual de la Compañía como colectivo apostólico, que, por primera vez en su historia tiene conciencia de que ya no era sólo europeo en su plural y diversa universalidad, la asamblea afirmó que la misión de los jesuitas de servicio de la fe y promoción de la justicia había de "ensancharse para incluir como dimensiones esenciales la proclamación del Evangelio, el diálogo y la evangelización de la cultura". Para la Congregación estas cuatro dimensiones

4 En la Contemplación llamada ad amorem, san Ignacio advierte que el amor se debe poner más en las obras que en las palabras (libro de los Ejercicios 230: 2). 
desarrollaban las intuiciones de los últimos treinta años y las plurales experiencias apostólicas de la Compañía universal. Se trata de una única misión, queha de desarrollarse en diversas dimensiones, con la colaboración de muchos agentes -seglares y jesuitas, mujeres y hombres, con los no creyentes, con personas de otras religiones, en comunidades de solidaridady que ha de incluir los nuevos rostros y lugares de la lucha por la justicia: solidaridad, dimensión ecológica (desarrollo sostenible), respeto y diálogo intercultural, papel de la mujer, lucha por los derechos humanos y las libertades, los problemas particulares de grupos como los refugiados, los emigrantes y otros sectores de marginación, etc.

Ante la vastedad de los nuevos problemas y perspectivas, la Congregación optó por desplazarse de la fenomenología de los problemas a las causas morales y culturales y pensar con rigor la capacidad de actuación, como había sugerido el padre Kolvenbach en 1991: no explotamos todas las posibilidades que tenemos como un cuerpo internacional. La Congregación debía alentar a la Compañía a establecer las estructuras necesarias para colaborar, con el debido discernimiento, con otras organizaciones. Una preocupación presente en las peticiones que habían llegado a Roma y en la propia Congregación era que quedase claro que la 'justicia' de la que se trata es una justicia que brota de la fe siempre orientada a los signos de los tiempos, que ahondan esa fe y sin cuyo cultivo el compromiso cristiano o no resulta sostenible 0 decae de su calidad cristiana. Las exigencias y el compromiso de la justicia deben ser integrados continuamente en la vida de fe para poder llegar a ser contemplativos en la transformación. La congregación hizo una lectura serena de la realidad y de las nuevas dimensiones de la justicia. La realidad que estaba debajo de la palabra justicia en 1975 ya no era la misma que en 1995, aunque la misión de la compañía consistiese en lo mismo: el anuncio del Evangelio y la promoción de la justicia que brota de este mismo anuncio.

La Congregación era consciente de ese cambio epocal y, porque reconocía el carácter histórico de esta lucha por la justicia, enumeraba seis nuevas dimensiones y situaciones de urgencia, a añadir al cambio estructural en las áreas socio-económicas y políticas y a otras tareas: (1) la creciente conciencia internacional de los derechos humanos, en su plural realización en las llamadas tres generaciones, en la lucha por la dignidad de la persona, y la apuesta de la Compañía por el trabajo en el seno de comunidades de solidaridad; (2) la conciencia de interdependencia de to dos los pueblos y de la mundialización económica acelerada, con sus consecuencias negativas (homogenización cultural, creciente fosa de desigualdad, consolidación dela 
exclusión social como uno de los más graves problemas), sin dejar de reconocer las muchas posibilidades abiertas para la solidaridad; (3) afirmación del valor primordial de la vida humana y de la cultura de la vida, insistiendo en una ecología de la humanización de la vida, y el interés creciente, de igual modo, por el medio ambiente y por un uso equitativo y sostenible de los recursos mundiales; (4) la conciencia, a partir de la experiencia vivida, de que el cambio social no consiste sólo en la transformación de las estructuras políticas y económicas, puesto que éstas tienen sus raíces en valores y actitudes socioculturales y la apuesta por buscar fórmulas de desarrollo plenamente humano; (5) la exclusión, como realidad omnipresente: marginación de África en el nuevo orden mundial, el difícil desarrollo, posterior al colapso, de los países de sistema totalitario en la Europa del Este, la amenaza a la identidad de los pueblos indígenas y la situación de exclusión y marginación de muchos grupos sociales, raciales, etc., así como, en general, la consolidación de un sistema de marginación y precariedad cultural; $y$, por último, (6) la existencia de millones de desplazados o refugiados en todo el mundo.

\section{Visibilidad de la misión para fecundar la dimensión social de toda la Compañía de J esús (Iniciativa social 1995, Congreso de Nápoles, 1997)}

Como hemos apuntado, la 34a Congregación general había comprobado que los conceptos de cambio social y de justicia social eran menos corrientes y menos fáciles de definir en 1995 que en 1975, y, por ello, se había preocupado por elaborar unos documentos con un tono y un lenguaje diferente, más radical y crítico. Desde 1989 el mundo había ido cambiando y las mismas palabras habían adquirido nuevas densidades y significaciones. En 1995 la Congregación reafirmó el servicio de la fe y la promoción de la justicia que brota de ese anuncio y está inseparablemente ligada a él, como el código, la columna vertebral y el principio de integración de la misión de la Compañía, y añadió, como resultado del examen de los veinte años transcurridos, dos dimensiones que desarrollan y completan la identidad misionera de la Compañía: el diálogo cultural y el diálogo interreligioso, ya que la Compañía había comprendido que to do cambio social hacia una mayor J usticia pasaba por la transformación cultural de la sociedad, lo que implicaba un encuentro y diálogo con las grandes tradiciones religiosas que informan todas las sociedades.

Al poco de acabar la 34ª Congregación general, el padre General, a través 
del nuevo Secretario para el Apostolado social, Michael Czerny, lanzaba la iniciativa del apostolado social como una especie de puente, tendido entre 1995 y 2005, al nuevo milenio. El apostolado social se vio obligado a redefinir su identidad. Entre el primer encuentro en Río de Janeiro (julio de 1995) y el de Nueva Delhi (marzo de 1997) se realizaron unos 30 encuentros en las distintas asistencias -entre ellos el de los jesuitas europeos, celebrado en Czestochowa, Polonia, en octubre de 1996-, y en marzo de ese año un coetus (comisión preparatoria) identificó los temas mayores del conjunto de respuestas recibidas y propuso la dinámica del Congreso de Apostolado social que se iba a celebrar en Nápoles, en junio de 1997, que reunió a unos 160 jesuitas de casi todo el mundo. El propósito del Congreso era contribuir a la renovación del apostolado social como un sector vital de la Compañía, planteando tres preguntas: ¿por qué existe el apostolado social?, ¿dónde surge y crece el apostolado social?, ¿cómo es el apostolado social?, que giraban sobre tres grandes núcleos: espiritualidad; contextos de trabajo; y, por último, medios y métodos. El documento Características, de 1998 responderá también a este esquema básico.

7. Un sector social, institucionalmente significativo (Características del Apostolado Social, 1998)

Un momento importantísimo en este proceso ha sido el documento Características del Apostolado Social (1998), que se anunció como provisional instrumento de trabajo en orden a un documento definitivo que había de haber visto la luz a primeros de 2000. El proceso, sin embargo, se ha alargado, pues el debate está siendo rico en perspectivas a integrar. El documento no pretendía describir el contenido del apostolado social, ni añadir nueva doctrina sobre lo mismo. Para una y otra cosa se remitía a las recientes Normas complementarias aprobadas tras la 34a Congregación general como resultado de su trabajo, que dotaba a la Compañía del instrumento normativo y orientativo supremo. Las Características se presentaban como guía y estímulo para la reflexión personal y grupal, de manera que sirviesen como instrumento para consolidar una nueva visibilidad del sector social.

Una aportación relevante de Características fue la distinción que estableció entre el sector social y la dimensión social. Mientras que desde 1975 la Compañía de Jesús había avanzado en la conciencia y en las acciones que tendían a hacer de la lucha por la justicia que brota del anuncio de la fe una de sus líneas prioritarias de definición y, por tanto, en la intensificación de la 
dimensión social de todas sus actividades apostólicas, las obras propias del sector del apostolado social y las presencias humanas en trabajos directamente sociales o en medios empobrecidos, se habían ido reduciendo poco a poco o perdido impulso apostólico. Por ello era urgente recuperar el contenido de un sector social de la Compañía, visible y con fuerte impulso apostólico. Aunque Características reconoce el pluralismo y la complejidad de la realidad social y, por ende, en la configuración actual del sector, no elude una definición vigorosa del apostolado. El apostolado o sector social está constituido por todas las instituciones y personas -jesuitas y seglaresque han recibido de la Compañía la misión explícita de trabajar en el campo socio-cultural; pueden ser proyectos, obras o instituciones explícitamente dedicados a la promoción de la justicia, así como escuelas, parroquias 0 comunidades insertas en zonas muy pobres 5 . Por otra parte, la conocida como dimensión social se sigue vinculando con la misión de toda la Compañía de Jesús y, por tanto, con los ministerios de todas las instituciones y de todos los jesuitas, sin excepción.

\section{El sector social toma cuerpo en el cuerpo de la Compañía (Carta sobre el} A postolado social del P. General, enero de 2000)

El año 2000 era el horizonte en que se había previsto la versión definitiva de las Características. Una carta del padre general debería respaldar el proceso de la Iniciativa social de 1995. El padre Kolvenbach escribió una importante Carta sobre el Apostolado social, haciendo referencia, desde el comienzo, al año jubilar del 2000 que celebraba toda la Iglesia como tiempo de conversión y de gracia, y a los cincuenta años transcurridos desde la vigorosa Instrucción sobre el Apostolado social del P. J anssens en 1949, que movilizó a toda la Compañía y dio origen, entre otras iniciativas, tanto a los numerosos CIAS, centros de investigación y acción social, en América latina, como a la misión obrera entre los jesuitas. El padre Kolvenbach reconoce como un hecho definitivamente adquirido que la inmensa mayoría de los jesuitas han integrado la dimensión social, y que de esa dimensión brota directamente el apostolado social, que encarna la dimensión social de la misión, la incorpora en compromisos concretos y la hace visible. Después de reconocer algunas fortalezas muy relevantes -entre ellas, la capacidad que

5 Según la segunda versión del documento, pág. 73*. La primera configuraba el apostolado social en tres niveles, de forma un tanto vacilante en el uso de los conceptos. 
el sector social tiene para la convocatoria de colaboradores valiosos, así como para suscitar vocaciones para la Compañía- y de testimoniar el misterioso don del martirio, el padre Kolvenbach subraya que existen, paradójicamente algunas debilidades preocupantes: la dispersión apostólica y pérdida de calidades, provocadas no sólo por razones internas a la Compañía sino por factores externos. Para que los grandes decretos de las últimas congregaciones $32^{a}$ y $34^{a}$ no se queden en puras declamaciones retóricas, advierte Kolvenbach de la necesidad de realizar un servicio efectivo y evangélicamente relevante. Para ello la carta afirma la importancia de ir redescubriendo y rediscerniendo, de manera continua, las demandas y desafíos actuales, en un así llamado diálogo de acción.

La carta del padre Kolvenbach hace explícitas las varias fases de la meto do logía a seguir y recuerda algunos principios generales que serán muy útiles a todas las instituciones y grupos apostólicos que deban llevar a cabo esa tarea antedicha, de acuerdo con las Características. Esta carta ha supuesto un estímulo para todos los jesuitas comprometidos en el sector social, un apoyo al proceso que se inició en España y Portugal hace diez años, así como a la dinámica puesta en marcha por la "iniciativa social". El discurso del padre Kolvenbach en la Universidad de Santa Clara (California), que publica este mismo número de RFS, es un llamamiento profético que ha reforzado la conciencia de los jesuitas en orden a un servicio de las instituciones y de las redes apostólicas en la misión de la justicia.

\section{Conclusión}

En las Jornadas de Alcalá de Henares (diciembre 2000) tuvo lugar lo que podríamos denominar refundación del sector social en las provincias de España y Portugal. Fueron un momento esperanzador para el sector social de las provincias y para el conjunto de la misión de la Compañía. La pluralidad de participantes - por primera vez un nutrido grupo de seglares vinculados a obras, instituciones o redes relacionadas con la Compañía, pero también jesuitas de distintas procedencias y sensibilidades- y el entusiasmo en el trabajo permitían concebir la esperanza de articular un apostolado social vigoroso y bien organizado como el que desea la Carta del padre Kolvenbach. Nos remitimos a la presentación de este número -ese texto puede leerse como crónica de las J ornadas y como guía de lectura del número entero- y a los textos publicados en el mismo para captar la orientación y el contenido de las J ornadas de Alcalá. 
La Compañía de J esús, en cuanto Cuerpo apostólico para una misión, está afrontada en los próximos años a la tarea que se desprende de este recorrido que hemos hecho por los últimos diez años: discernimiento de las fortalezas y debilidades manifestadas en este período, con especial atención a la conflictividad que esta opción ha generado. De esta lectura podrá obtenerse la clave para revitalizar la praxis institucional que dote de un sector vivo y activo a cada territorio apostólico de la Compañía y a ésta en su conjunto. Poner en acto las directrices de la Carta del General va a requerir tanto esta lucidez y audacia indicadas, como desarrollar una fuerte espiritualidad que fundamente el compromiso apostólico por la justicia. Para ello será necesaria la convergencia de las tres almas o culturas presentes, en desigual proporción y muy relacionadas con segmentos de edad, en el sector social de nuestras provincias: quienes están más llamados al análisis de la realidad y a la reflexión (centros universitarios de estudio, grupos como Fomento social, iniciativas como Migrastudium, Instituto de Migraciones, Instituto de Derechos Humanos, centros fe-cultura, la RFS), quienes perciben con intensidad la importancia del trabajo político y de transformación estructural en el cuarto mundo ( grupos de apoyo de voluntariados, centros fe-cultura) o en el tercero (Intermón, Alboán, Entreculturas) y, por último, los que han hecho la opción por la inserción en el mundo obrero (generación de la misión obrera) o de la exclusión (generación del trabajo junto a la marginación, voluntariados). Si los jesuitas y seglares que compartimos la misión del servicio de la justicia que brota del anuncio de la fe, somos capaces de generar las condiciones del diálogo social y de la convergencia en una espiritualidad cristiana fuerte, habremos respondido al reto que, en este cambio de siglo, nos presenta la misión de Cristo, de la que deseamos ser auténticos servidores. 


\section{Referencias de documentos y hechos}

- 1990 Encuesta Fe y J usticia. Resultados. J ornadas Fe y J usticia, Gijón, 2830 de diciembre 1990, 147 pp.

- 1990 J ornadas Fe-J usticia (Gijón, 28-30 diciembre de 1990). Información sj 22 (1991) no 25 (mayo-junio), pp. 73-108

- 1993 Pedagogía ignaciana. Un planteamiento práctico. CONEDSI, 3+57 pp.

- 1994 Foro Fe-J usticia '94 (Alcalá de Henares, 4-6 abril 1994). Información s.j. 26 (1995), no 45 (septiembre-octubre), pp. 157-216

- 1994III J ornadas sobre fe e increencia. Nuestra fe y sus motivaciones ante los desafíos de hoy. (Jornadas de Majadahonda, 8-11 septiembre 1994), edita Compañía de Jesús en España, diciembre 1994, 104 pp.

- 1995 Congregación general 34ạ, Roma, enero-marzo de 1995, edita Compañía de J esús en España / edit. Sal Terrae, 545 pp.

- 1995-2005 Iniciativa para el A postolado Social, Secretariado Apostolado Social S.I., Roma.

- 1995 Constitucionesy Normas complementarias de las Constituciones de la Compañía de J esús, aprobadas por la Congregación general XXXIV, Bilbao - Santander, edit. Mensajero - edit. Sal Terrae, 543 pp. (espec. nn. 298-302).

- 1997 Congreso de Nápoles, junio de 1997.

- 1998 Características del A postolado Social de la Compañía de Jesús, en Promotio iustitiae no 69, $8+100$ pp.

- 2000 Peter-Hans KOLVENBACH, Carta sobre el Apostolado social, en Promotio iustitiae no 73 (mayo 2000) pp. 19-24

- 2000 J ornadas de sociales de la Compañía de J esús, Alcalá de Henares (710 de diciembre de 2000), en Revista de Fomento Social 55 n 220 (octubrediciembre).

\section{Algunos textos de referencia}

- Alfonso ÁLVAREZ BOLADO (1994) Evolución del concepto de justicia en los últimos veinte años, en 20 Jornadas educativas nacionales (1990), Socialización y humanismo, Madrid (1990), CONEDSI, pp. 37-49. 
- Alfonso ÁLVAREZ BOLADO (1995) Misión y carisma. La Compañía de Jesús reformula su mi sión en el mundo, en Sal Terrae 83 (septiembre) pp. 587-597

- J ean-Yves CALVEZ (1995) Fe y justicia: la dimensión social de la evangelización, Santander, ed. Sal Terrae, Presencia teológica no 22, 248 pp.

- Ildefonso CAMACHO LARAÑA (1990) La opción fe- justicia como clave de evangelización en la Compañía de Jesús y el Generalato del Padre Arrupe, en Manresa 62, pp. 219-246

- Ildefonso CAMACHO LARAÑA (1996) La promoción de la justicia en la Congregación General XXXIV, en Estudios eclesiásticos 71, pp. 49-85.

- Michel CZERNY (1996) Iniciativa del Apostolado social, 1995-1999, en Promotio lustitiae $\mathrm{n}$-64, pp. 33-37

- J osep M. RAMBLA et al. (1990) Tradición ignaciana y solidaridad con los pobres (col. Manresa no 4), Bilbao-Santander, edit. Mensajero-Sal Terrae, $187 \mathrm{pp}$.

- José Juan ROMERO (1995) Los jesuitas y la justicia: aportaciones de la Congregación General 34ạ, en Revista de Fomento Social 50, no 199 (julioseptiembre), 329-357

- Rafael YUSTE MOYANO (1999), Tres paradigmas del Trabajo Social, en Revista de Fomento Social 54, no 213 (enero-marzo), pp. 47-62. 